\title{
Fibroblast growth factor-21 (FGF21) administration to early-lactating dairy cows. II. Pharmacokinetics, whole-animal performance, and lipid metabolism
}

\author{
L. S. Caixeta, ${ }^{1 *}$ S. L. Giesy, ${ }^{1 *}$ C. S. Krumm, ${ }^{1}$ J. W. Perfield 2 nd, ${ }^{2}$ A. Butterfield,${ }^{2}$ and Y. R. Boisclair ${ }^{1} \dagger$ \\ ${ }^{1}$ Department of Animal Science, Cornell University, Ithaca, NY 14853 \\ ${ }^{2}$ Lilly Research Laboratories, Eli Lilly and Company, Indianapolis, IN 46285
}

\begin{abstract}
Dairy cows cope with severe energy insufficiency in early lactation by engaging in intense and sustained mobilization of fatty acids from adipose tissue. An unwanted side effect of this adaptation is excessive lipid accumulation in the liver, which in turn impairs hepatic functions. Mice experiencing increased hepatic fatty acid flux are protected from this condition through coordinated actions of the newly described hormone fibroblast growth factor-21 (FGF21) on liver and adipose tissue. The possibility of an analogous role for FGF21 in dairy cows is suggested by its rapid increase in plasma levels around parturition followed by chronically elevated levels in the first few weeks of lactation. To test this hypothesis, dairy cows were randomly assigned on d $12.6 \pm 2.2$ ( \pm standard error) of lactation to receive either an excipient (control; $\mathrm{n}=6$ ) or recombinant human FGF21 ( $\mathrm{n}=7$ ), first as an FGF21 bolus of $3 \mathrm{mg} / \mathrm{kg}$ of body weight (BW) followed $2 \mathrm{~d}$ later by a constant i.v. infusion of FGF21 at a rate of $6.3 \mathrm{mg} /$ $\mathrm{kg}$ of metabolic BW for 9 consecutive days. After bolus administration, human FGF21 circulated with a halflife of $194 \mathrm{~min}$, and its constant infusion increased total plasma concentration 117 -fold over levels in excipientinfused cows. The FGF21 treatment had no effect on voluntary feed intake, milk yield, milk energy output, or net energy balance measured over the 9-d infusion or on final BW. Plasma fatty acids circulated at lower concentrations in the FGF21 group than in the control group for the 8-h period following bolus administration, but this reduction was not significant during the period of constant i.v. infusion. Treatment with FGF21 caused a 50\% reduction in triglyceride content in liver biopsies taken at the end of the constant i.v. infusion without altering the mRNA abundance of key genes involved in the transport, acyl coenzyme A activation,
\end{abstract}

Received March 27, 2019.

Accepted July 14, 2019.

*These authors contributed equally to this work.

†Corresponding author: yrb1@cornell.edu or oxidation of fatty acids. In contrast, FGF21 treatment ablated the recovery of plasma insulin-like growth factor-1 seen in control cows during the 9-d i.v. infusion period despite a tendency for higher plasma growth hormone. This effect was associated with increased hepatic mRNA abundance of the intracellular inhibitor of growth hormone receptor trafficking, LEPROT. Overall, these data confirm the ability of FGF21 to reduce lipid accumulation in bovine liver and suggest the possibility that FGF21 does so by attenuating the hepatic influx of adipose tissue-derived fatty acids.

Key words: $\beta$-hydroxybutyrate, fatty acid, growth hormone resistance, insulin-like growth factor-1, liver

\section{INTRODUCTION}

Dairy cows experience a severe energy insufficiency in early lactation as a consequence of mammary nutrient demands occurring in the absence of adequate compensatory feed intake (Bell, 1995; Drackley et al., 2001; Boisclair et al., 2006). Dairy cows close the energy gap in part by engaging in intense and sustained mobilization of fatty acids from adipose tissue. This is indicated in the first few days of lactation by peaks of plasma fatty acids in the range of 600 to $1,000 \mu \mathrm{M}$ reflecting daily mobilization rates of 2.2 to $3.7 \mathrm{~kg}$ (Drackley et al., 2001) and by sufficient amounts of fatty acids mobilized over the first month of lactation to cover $30 \%$ of total energy requirements (Bell, 1995; Drackley et al., 2001). One drawback of accelerated fatty acid mobilization, however, is ectopic lipid accumulation, with the liver being particularly vulnerable to this condition (Bobe et al., 2004; Geelen and Wensing, 2006). Liver susceptibility to lipid accumulation reflects its ability to extract 20 to $25 \%$ of incoming fatty acids irrespective of circulating concentrations (Drackley et al., 2001). With the elevated fatty acid concentration of early lactation, hepatic uptake far exceeds disposal by oxidation and secretion as very low density lipoprotein (VLDL; Drackley et al., 2001). The moderate to severe lipidosis that follows not only impairs hepatic functions such as gluconeogenesis but also is negatively associ- 
ated with whole-animal outcomes such as reproduction (Rukkwamsuk et al., 1999; Geelen and Wensing, 2006).

The identification of excessive lipid mobilization and insufficient hepatic disposal as root causes of liver lipidosis has prompted efforts to identify hormones involved in their regulation. This work has implicated low plasma insulin and growth hormone $(\mathbf{G H})$-dependent potentiation of adipose tissue response to catecholamines as drivers of fatty acid mobilization in early lactation (Vernon, 2005; Boisclair et al., 2006) and has shown that glucagon therapy limits liver triglyceride accumulation (Nafikov et al., 2006). Work in rodents has recently implicated fibroblast growth factor-21 (FGF 21) as another potential important regulator of fatty acid metabolism (Fisher and Maratos-Flier, 2016; BonDurant and Potthoff, 2018). Fibroblast growth factor-21 belongs to the fibroblast growth factor (FGF) superfamily of growth factors, but, unlike most other members, it lacks the high-affinity heparin domain needed for FGF retention through proteoglycan binding (Itoh et al., 2016). Therefore, FGF21 can leave the site of synthesis and act as a hormone. In the mouse, virtually all circulating FGF21 is produced in the liver, where production depends on the presence of the transcription factors peroxisome proliferator-activated receptor- $\alpha$ (PPARA) and cAMP responsive element binding protein 3-like 3 (CREB3L3 or CREBH) and the deacetylase sirtuin 1 (SIRT1; Fisher and MaratosFlier, 2016). Mice lacking these regulatory proteins develop more severe steatosis than their wild-type counterparts when fasted or offered high-fat diets, and this condition can be prevented by exogenous FGF21 therapy (Inagaki et al., 2007; Li et al., 2014; Park et al., 2016). Mechanistic studies have traced the reduction of liver steatosis by FGF21 to stimulation of fatty acid disposal in the liver and repression of lipolysis in adipose tissue (Arner et al., 2008; Li et al., 2009; Potthoff et al., 2009; Fisher et al., 2014).

The possibility that a single hormone could limit hepatic lipid accumulation through coordinated actions on adipose tissue and liver is highly relevant to earlylactating dairy cows. In our previous work, we uncovered a dynamic increase in plasma FGF21 at the onset of lactation and identified liver as its primary source (Schoenberg et al., 2011). More recently, we implicated plasma fatty acids as a key factor driving hepatic FGF21 production and increasing circulating FGF21 in cattle (Caixeta et al., 2017). At this time, however, no information is available on the role of FGF21 in cattle and, more specifically, on the possibility that it limits hepatic accumulation of lipids in early lactation. Our results indicate that exogenous FGF21 reduces the accumulation of triglyceride in liver and does so in the absence of detrimental effects on performance.

\section{MATERIALS AND METHODS}

\section{Animals and Design}

All procedures were conducted with the approval of the Cornell University Institutional Care and Use Committee. Thirteen Holstein dairy cows of uniform parity $(2.3 \pm 0.2 ; \pm \mathrm{SE})$ and body condition $(3.5 \pm 0.2)$ were selected. Cows were moved on d $9.6 \pm 2.2$ of lactation to individual stalls under a controlled environment $\left(20^{\circ} \mathrm{C}\right.$, light on $\left.0500-2100 \mathrm{~h}\right)$ and fitted with bilateral intrajugular catheters (Tygon S-54-HL, 1.02-mm i.d. $\times$ 1.78-mm o.d.; Saint-Gobain Performance Plastics, Akron, $\mathrm{OH})$. They were offered nonlimiting amounts of a dry TMR (Table 1 ) every $2 \mathrm{~h}$ using in-house automatic feeders and were milked twice daily at 0700 and $1700 \mathrm{~h}$.

Cows were then randomly allocated to an excipient solution (control; $\mathrm{n}=6$ ) or recombinant human FGF21 $(\mathrm{n}=7)$ and studied in 2 consecutive phases. On d 11.6 \pm 2.2 , basal blood samples were obtained every $2 \mathrm{~h}$ between 0800 and $1200 \mathrm{~h}$ followed by measurement of $\mathrm{BW}($ control $=636.0 \pm 24.0 \mathrm{~kg} ; \mathrm{FGF} 21=648.0 \pm 24.9$ $\mathrm{kg})$. In the first phase, treatments were administered as

Table 1. Ingredient and nutrient composition of the diet

\begin{tabular}{lr}
\hline Item & \% of DM \\
\hline Ingredient & \\
Alfalfa hay & 31.44 \\
Grass hay & 9.44 \\
Corn grain, finely ground & 23.17 \\
Corn meal & 9.80 \\
Distillers grains & 6.16 \\
Wheat middlings & 5.91 \\
Soybean hulls & 5.68 \\
Soybean meal, cooker processing ${ }^{1}$ & 1.96 \\
Canola meal & 1.96 \\
Molasses & 1.43 \\
Bypass fat & 0.91 \\
Sodium bicarbonate & 0.69 \\
Salt & 0.40 \\
Calcium carbonate & 0.35 \\
Blood meal & 0.31 \\
Urea & 0.22 \\
Magnesium oxide, $54 \%$ & 0.05 \\
Selenium, 0.06\% & 0.04 \\
Vitamin A, D, E premix ${ }^{2}$ & 0.03 \\
Rumensin 90 & \\
Chemical analysis & 0.01 \\
CP & \\
ADF & 18.06 \\
NDF & 21.60 \\
Starch & 34.73 \\
Crude fat & 20.98 \\
Ca & 3.80 \\
P & 7.08 \\
1AminoPt (Ag Pros & 0.96 \\
& 0.40 \\
\hline
\end{tabular}

${ }^{1}$ AminoPlus (Ag Processing Inc., Omaha, NE).

${ }^{2}$ Contained 30,464 IU $/ \mathrm{kg}$ vitamin $\mathrm{A}, 5,862 \mathrm{IU} / \mathrm{kg}$ vitamin $\mathrm{D}$, and 93,784 IU/kg vitamin E.

${ }^{3}$ Elanco Animal Health (Greenfield, IN). 
a single intrajugular bolus at $0800 \mathrm{~h}$ on $\mathrm{d} 12.6 \pm 2.2$ of lactation. The FGF21 dose was $3 \mathrm{mg} / \mathrm{kg}$ of BW and was selected on the basis of positive responses when given as a single injection in the mouse ( $\mathrm{Xu}$ et al., 2009b). The dose was prepared with the human FGF21 variant LY2405319 with 78\% identity with mature bovine FGF21 and bioactivity in cattle (Krumm et al., 2019); LY2405319 was engineered for enhanced in vivo stability and to retain full biological activity (Adams et al., 2013; Kharitonenkov et al., 2013). It was produced in Pichia pastoris, purified to homogeneity using reversed-phase and anion-exchange chromatography, and prepared as a $33 \mathrm{mg} / \mathrm{mL}$ solution in an excipient solution of $10 \mathrm{~m} M$ citrate, $150 \mathrm{mM} \mathrm{NaCl}$, pH 7.0 (Eli Lilly, Indianapolis, IN; Kharitonenkov et al., 2013). The LY2405319 solution was kept frozen until use, as done in previous studies in humans and monkeys (Adams et al., 2013; Gaich et al., 2013). Blood samples were obtained at fixed times relative to bolus administration $(-60,-30,0,1,5,10,20,40$, and $60 \mathrm{~min}$ and 1.5, 2, 3, $4,6,8,10$, and $12 \mathrm{~h}$ ), immediately mixed with heparin $(15 \mathrm{IU} / \mathrm{mL})$, and centrifuged at $3,000 \times g$ for $15 \mathrm{~min}$ at $4^{\circ} \mathrm{C}$. Resulting plasma was stored at $-20^{\circ} \mathrm{C}$ until being analyzed for plasma FGF21 and fatty acids.

The second phase was initiated $2 \mathrm{~d}$ later at $0800 \mathrm{~h}$ and involved continuous intrajugular infusion of either excipient or FGF21 solution for 9 consecutive days. The daily FGF21 dose was $6.3 \mathrm{mg} / \mathrm{kg}$ of metabolic BW and was selected on the basis of positive responses when given chronically in rhesus monkeys (Adams et al., 2013). The LY2405319 was prepared in an excipient solution as described above, and both the excipient and LY2405319 solutions were infused at the fixed rate of $5 \mathrm{~mL} / \mathrm{h}$ using a syringe pump. Blood was collected every $2 \mathrm{~h}$ between 0800 and $1200 \mathrm{~h}$ on d 1, 3, and 8 of infusion and at $0800 \mathrm{~h}$ on other days. An i.v. glucose tolerance test (GTT) was performed at $1400 \mathrm{~h}$ on d 8 of the chronic infusion. The glucose dose was $0.25 \mathrm{~g} / \mathrm{kg}$ of BW administered as a dextrose solution (50\% wt/ vol; VetOne, Boise, ID). Blood samples were collected at $-60,-30,-15,-5,5,10,20,30,60,90$, and 120 min relative to administration of the glucose bolus. All blood samples collected during this phase were processed to plasma as described above. Finally, a liver biopsy was obtained at the end of chronic infusion on d 9 followed by measurement of BW. The biopsy was obtained after surgical preparation and local anesthesia via percutaneous puncture with a trocar as previously described (Giesy et al., 2012; Caixeta et al., 2017). Biopsies were snap-frozen in liquid nitrogen and stored at $-80^{\circ} \mathrm{C}$ until further analysis.

Variables measured at the start and end of treatment included BW and body condition as previously described (Block et al., 2001). Variables measured throughout the treatment period included daily feed intake and milk weight and composition at every milking. The nutrient and chemical composition of the TMR was determined using wet chemistry analysis, and the composition of milk was determined using infrared analysis (Dairy One Cooperative Inc., Ithaca, NY). Equations published by NRC (2001) were used to calculate the TMR energy content and milk energy output. Individual energy intake and milk energy output averaged over the entire treatment period were used to calculate net energy balance as described previously (Block et al., 2001).

\section{Analysis of Metabolites and Hormones}

Plasma fatty acids and BHB were analyzed using spectrophotometric methods based on the enzymes acyl coenzyme A-oxidase and BHB dehydrogenase, respectively (Caixeta et al., 2017). The plasma fatty acid response area during the GTT was calculated between 0 and $120 \mathrm{~min}$ and was corrected for baseline concentrations (mean of concentrations at $-60,-30$, -15 , and -5 min; Sechen et al., 1989; Ehrhardt et al., 2001). Total and intact FGF21 were determined using an in-house sandwich FGF21 ELISA differing only in the antibody used for detection (rabbit polyclonal against human FGF21 for total FGF21; mouse monoclonal against the $\mathrm{C}$ terminal FGF21 region for intact FGF21) and validated in bovine plasma (Schoenberg et al., 2011; Caixeta et al., 2017). Growth hormone and IGF-1 were measured using in-house RIA validated in bovine plasma (Block et al., 2001; Leury et al., 2003). Inter- and intra-assay coefficients of variation were $<10$ and $<9 \%$, respectively, for metabolite assays and $<9$ and $<9 \%$, respectively, for hormone assays.

Liver triglycerides were measured using a method validated in cattle involving extraction of total lipids with the Folch procedure followed by determination of triglycerides using the colorimetric Hantzsch condensation method (Schoenberg et al., 2011; Caixeta et al., 2017). Total levels of ceramides and diacylglycerol in liver were measured using methods we previously described (Estridge et al., 2017; Pillon et al., 2018). In brief, liver samples were homogenized in a Qiagen (Valencia, CA) TissueLyzer II followed by addition of an internal standard mixture consisting of ${ }^{15} \mathrm{~N},{ }^{13} \mathrm{C} 3-$ ceramide-16:0 and diacylglycerol 15:0/15:0 (Eli Lilly). Lipids were isolated using 2-phase extraction of aqueous methanol and chloroform. Lipidomics was conducted via flow injection electrospray ionization-tandem MS using a 5600 TripleTOF system (AB Sciex, Framingham, MA). The mass spectra were acquired in 2 stages. In the first stage, the time of flight spectra were scanned with minimal collision energy from 100 to 1,200 Da with high resolution. The second stage consisted of time of 
flight product ion scans of 611 precursor masses from 349.199 to 959.809 isolated with a resolution of $0.7 \mathrm{Da}$ and changed stepwise in 1.001-Da increments. Lipids were identified in the second stage by precursor and product ion pairs predicted by the analyte species and lipid class. Levels of individual ceramide and diacylglycerol species were quantified by the ratio of analyte to internal standard and summed to obtain total levels of diacylglycerol and ceramide.

\section{Pharmacokinetic Analysis of Human FGF21}

The concentrations of total plasma FGF21 in postbolus samples were analyzed using noncompartmental analyses with a commercial software (PK Solutions 2.0, Summit Research Services, Montrose, CO). This software uses a curve-stripping procedure to resolve the concentration-time curves into a series of exponential terms that correspond to the kinetic phases of this hormone in circulation. The initial total FGF21 concentration was estimated through linear extrapolation of the first 2 plasma concentration values to time zero. Area under the concentration-time curve from 0 to $12 \mathrm{~h}\left(\mathrm{AUC}_{0-12 \mathrm{~h}}\right)$ was estimated using the trapezoid method up to the last measured concentration at 12 $\mathrm{h}$ post-bolus. The apparent terminal disposition rate constant $\left(\lambda_{z}\right)$ was determined using linear regression analysis of the terminal portion of the log plasma concentration-time curve. Elimination half-life $\left(t_{1 / 2}\right)$ and clearance rate were calculated as $\ln (2) / \lambda_{z}$ and dose/ $\mathrm{AUC}_{0-12 \mathrm{~h}}$, respectively.

\section{RNA Extraction and Analysis of Gene Expression}

Liver samples were lysed with Qiazol (Qiagen) followed by total RNA purification using RNeasy Mini columns and on-column RNase-free DNase treatment (Qiagen). Quality of RNA was determined using the RNA Nano Lab Chip kit and bioanalyzer (Agilent, Palo Alto, CA) with all samples having an RNA integrity number $>7.5$. Reverse transcription reactions were performed with $2 \mu \mathrm{g}$ of total RNA in a total volume of $20 \mu \mathrm{L}$ with the high-capacity cDNA reverse transcription kit and RNase inhibitor (Applied Biosystems, Foster City, CA). Gene expression was analyzed using quantitative real-time PCR using Power SYBR Green Mix (Applied Biosystems). Real-time PCR assays were performed in duplicate with a total $25-\mu \mathrm{L}$ reaction volume containing $500 \mathrm{n} M$ concentration of each primer and reversetranscribed RNA (25 ng except $2.5 \mathrm{ng}$ for the internal standard gene $18 S$ ). The sequences of all primers used are given in Supplemental Table S1 (https://doi.org/10 .3168/jds.2019-16696). Primer pairs were designed us- ing Primer-BLAST software (http://www.ncbi.nlm.nih .gov/tools/primer-blast/). For all genes, each member of the primer pair was located in adjoining exons and shown by blast analysis to anneal exclusively to the target sequence. For all primer pairs, amplification was greater than $95 \%$ efficient and yielded a single product as shown by melting curve analysis. Data were analyzed using a relative standard curve based on a serial 2 -fold dilution of pooled cDNA prepared from liver and normalized to the geometric mean of $18 S$ and B2M.

\section{Statistical Analysis}

Data were analyzed using the MIXED procedure of SAS version 9.3 (SAS Institute Inc., Cary, NC). Data collected at a single time point or collated over the treatment period were analyzed using a model accounting for treatment (control vs. FGF21) as fixed effect and cow as the random effect. Data collected over time were analyzed using repeated measures, and the model accounted for treatment (control vs. FGF21) and time as fixed effects and cow as the random effect. Cow was subjected to 6 covariance structures (first-order autoregressive, heterogeneous first-order autoregressive, compound symmetry, heterogeneous compound symmetry, first-order antedependence, and Toeplitz). The structure yielding the smallest Akaike information criterion was selected. A covariate corresponding to data collected immediately before bolus was included in this model. Statistical significance and tendency were respectively set at $P<0.05$ and $P<0.10$ for main effects and at $P<0.10$ and $P<0.15$ for the FGF21 $\times$ Time interactions.

\section{RESULTS}

\section{Plasma Profile of Human FGF21 During Acute and Chronic Infusion}

On d $12.6 \pm 2.2$ of lactation, dairy cows received a single i.v. bolus of excipient or $3 \mathrm{mg}$ of human FGF21/ $\mathrm{kg}$ of BW followed by blood sampling over the next $12 \mathrm{~h}$. The plasma concentration of total FGF21 before bolus in these cows was $5.8 \pm 1.7 \mathrm{ng} / \mathrm{mL}$ and remained at this level in cows receiving the excipient bolus. In contrast, the plasma concentration of total FGF21 reached $42,150 \mathrm{ng} / \mathrm{mL}$ within $5 \mathrm{~min}$ in the FGF21 group, followed by a steady decline to $179 \mathrm{ng} / \mathrm{mL}$ after $12 \mathrm{~h}$ (Figure 1A). Analysis of the plasma total FGF21 concentration-time curve predicted a maximal concentration of $45,275 \mathrm{ng} / \mathrm{mL}$ at time 0 and an average elimination $t_{1 / 2}$ of $194 \mathrm{~min}$ (Table 2). Additional kinetic parameters are given in Table 2. 
A

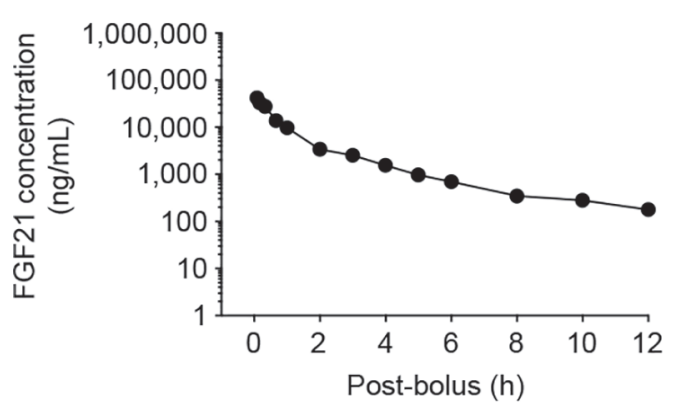

C

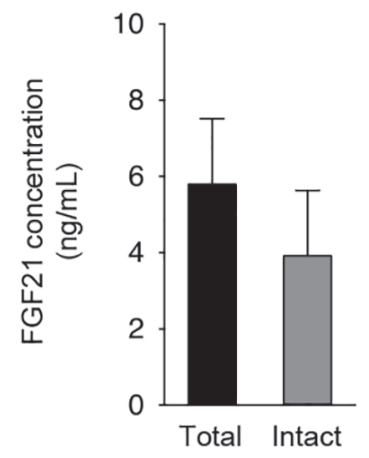

B

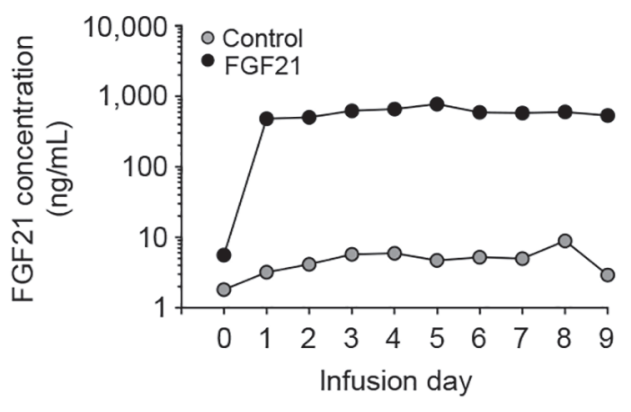

D

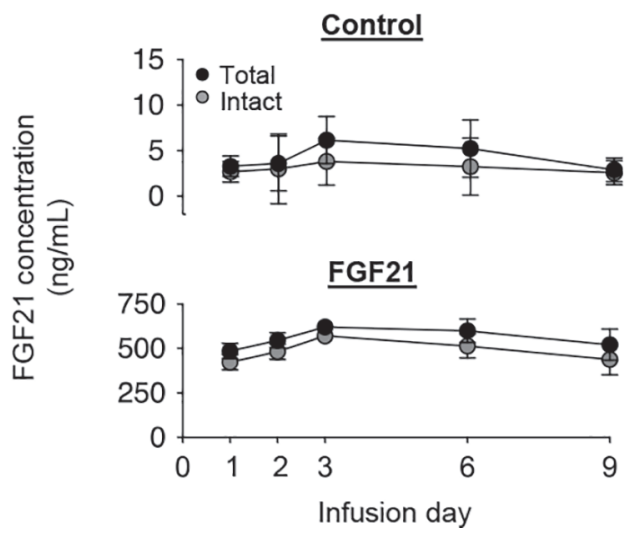

Figure 1. Pharmacokinetics of fibroblast growth factor-21 (FGF21) in early-lactating dairy cows. An excipient (control) or a human FGF21 solution were given i.v. as boluses on d $12.6 \pm 2.2$ of lactation (FGF21 dose $=3 \mathrm{mg} / \mathrm{kg}$ of BW) and as constant infusions (FGF21 dose $=6.3$ $\mathrm{mg} / \mathrm{kg}$ of metabolic BW per day) starting on d $14.6 \pm 2.2$. Blood samples were collected over the 12-h period following bolus administration and daily over the 9-d constant infusion, and plasma was analyzed for FGF21 concentration. (A) Plasma FGF21 concentration after FGF21 bolus administration. Data shown are plasma FGF21 concentrations corrected for basal concentration measured immediately before bolus administration $(5.6 \pm 1.3)$. Each point represents the LSM \pm SE of 7 cows. The pooled SE was $1,421 \mathrm{ng} / \mathrm{mL}$. (B) Plasma FGF21 concentration during the 9-d constant infusion period. Each point represents the LSM of 6 to 7 cows. The pooled SE was $1.5 \mathrm{ng} / \mathrm{mL}$ for the control group and $27.3 \mathrm{ng} /$ $\mathrm{mL}$ for the FGF21 group. (C) Total and intact plasma FGF21 concentrations during the pretreatment period. Each bar represents the LSM \pm SE of 13 cows. (D) Total and intact plasma FGF21 concentrations during the 9-d constant infusion period. Each point represents the LSM \pm SE of 6 to 7 cows.

Treatments were resumed $2 \mathrm{~d}$ later via constant i.v. infusion. Infusion of FGF21 led to a plasma concentration of total FGF21 of $486 \pm 39.8 \mathrm{ng} / \mathrm{mL}$ after $1 \mathrm{~d}$ of infusion and an average concentration of $597 \pm 27.3$

Table 2. Pharmacokinetic parameters of fibroblast growth factor-21 (FGF21) after a single bolus injection ${ }^{1}$

\begin{tabular}{|c|c|}
\hline Parameter $^{2}$ & Average $\pm \mathrm{SE}$ \\
\hline $\begin{array}{l}\mathrm{C}_{\mathrm{i}}(\mathrm{ng} / \mathrm{mL}) \\
\mathrm{AUC}_{0-12 \mathrm{~h}}\left(\mathrm{ng} \cdot \mathrm{min} \cdot \mathrm{mL}^{-1}\right) \\
\mathrm{Cl}\left(\mathrm{mL} \cdot \mathrm{min}^{-1} \cdot \mathrm{kg}^{-1}\right) \\
\text { Elimination } \mathrm{t}_{1 / 2}(\mathrm{~min})\end{array}$ & $\begin{aligned} 45,275 & \pm 4,156 \\
2,324,850 & \pm 175,543 \\
1.3 & \pm 0.1 \\
194 & \pm 29\end{aligned}$ \\
\hline
\end{tabular}

${ }^{1}$ Dairy cows received a single i.v. bolus of human FGF21 (3 mg/kg) on d $12.6 \pm 2.2$ of lactation $(\mathrm{n}=7)$.

${ }^{2} \mathrm{C}_{\mathrm{i}}=$ initial concentration; $\mathrm{AUC}_{0-12 \mathrm{~h}}=$ area under the concentrationtime curve from 0 to $12 \mathrm{~h} ; \mathrm{Cl}=$ clearance rate; $\mathrm{t}_{1 / 2}=$ half-life. $\mathrm{ng} / \mathrm{mL}$ over the 9-d infusion (Figure 1B). This average FGF21 concentration represents a 117-fold increase over the plasma FGF21 concentration of $5.1 \pm 1.5 \mathrm{ng} /$ $\mathrm{mL}$ measured in the control group over the same period.

Human FGF21 is susceptible to inactivation through proteolytic cleavage at its carboxyl-terminal end (Hecht et al., 2012). To determine whether this processing occurs in cattle, plasma was reassayed, with the intact ELISA detecting only FGF21 with an intact carboxylterminal end. As shown in Figure 1C, the intact and total FGF21 assays yielded comparable plasma concentrations during the pretreatment period. Similarly, plasma FGF21 concentrations measured during the treatment period did not differ significantly between intact and total FGF21, including in cows receiving the human FGF21 infusion (Figure 1D). 
Increased Plasma FGF21 Has No Effect on Performance in Early Lactation

Fibroblast growth factor-21 had no effect on the profile of feed intake, milk yield, or milk energy output over the 9-d infusion period (Figure 2A). A similar lack of FGF21 effect was seen on milk production expressed as FCM and on milk components, with the exception of a higher milk protein content in FGF21-treated cows (Table 3). The net energy balance during the treatment period was similarly negative at -15.7 and $-14.9 \mathrm{Mcal} / \mathrm{d}$ for control and FGF21 cows, respectively (Figure 2B). Consistent with a lack of effect on energy balance, final BW and BCS did not differ between treatments (Table 3 ).

\section{Effect of Increased Plasma FGF21 on Lipid Metabolism}

Administration of FGF21 to rodents and primates reduces various lipid fractions in plasma, including fatty acids (Li et al., 2009; Xu et al., 2009a; Gaich et al., 2013). To determine whether similar effects were seen in early-lactating dairy cows, plasma fatty acids were analyzed in samples collected during the $12 \mathrm{~h}$ following bolus and during the 9-d infusion. Following bolus administration, plasma fatty acids circulated at lower concentrations in the FGF21 group than in the control group for most of the 12-h sampling period (Figure $3 \mathrm{~A}$; FGF21 $\times$ Time, $P=0.047)$. As expected, plasma fatty acids declined over the 9-d infusion, but the fatty acid-reducing effect of FGF21 was no longer significant (Figure 3B; Time, $P=0.004$ ). A statistical tendency was observed for plasma BHB, with numerically lower concentrations in the FGF21 group than in the control group between d 2 and 6 of infusion (FGF21 $\times$ Time, $P=0.15)$. Finally, we asked whether FGF21 treatment affected the plasma fatty acid profile during a GTT performed on d 8 of infusion. The GTT procedure led to identical increases and profiles of plasma insulin in both groups (Krumm et al., 2019), causing dynamic reductions in plasma fatty acid concentrations over the first $60 \mathrm{~min}$ (Figure 3D; Time, $P<0.001$ ). However, FGF21 treatment had no effect on either the profile or the response area of plasma fatty acids.

A second major consequence of FGF21 therapy in laboratory animals is a reduction in liver lipids (Inagaki et al., 2007; Xu et al., 2009a; Fisher et al., 2014). Accordingly, we assayed various lipid species in biopsies taken on d 9 of chronic infusion. The FGF21 treatment had no effect on total diacylglycerol and ceramide levels but caused a 50\% reduction in triglyceride content (Figure 4A; $P=0.036$ ). This effect was not associated with altered expression of genes encoding

\section{A}
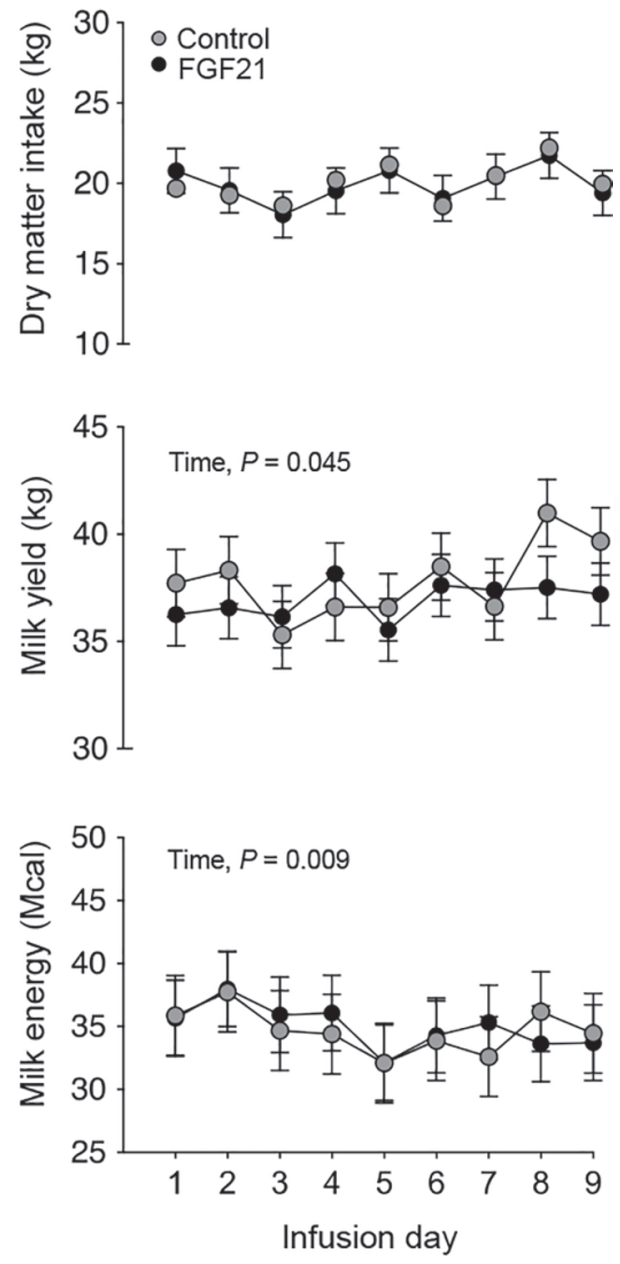

B

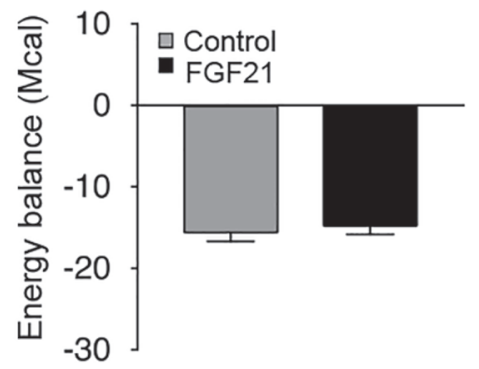

Figure 2. Effect of chronic administration of fibroblast growth factor-21 (FGF21) on production-related variables. Dairy cows received a constant i.v. infusion of an excipient (control) or human FGF21 (6.3 $\mathrm{mg} / \mathrm{kg}$ of metabolic BW per day) starting on d $14.6 \pm 2.2$ of lactation and lasting for 9 consecutive days. (A) Dry matter intake, milk yield, and milk energy were measured daily. Each point represents the LSM $\pm \mathrm{SE}$ of 6 to 7 cows. The significant effect of Time is reported. (B) Net energy balance was calculated for each cow over the 9 -d period as the difference between energy intake and output (milk energy and maintenance). Each bar represents the LSM \pm SE of 6 to 7 cows. 
proteins involved in fatty acid transport (SLC27A5), acyl coenzyme A activation of fatty acids (ASCL1), or mitochondrial fatty acid oxidation and ketogenesis ( $A C A D M, A C A D L$, and $H M G C S 2$; Figure 4B).

\section{Effect of Increased Plasma FGF21 on the Hepatic GH-IGF-1 System}

Chronic increases in plasma FGF21 in rodents impair hepatic GH action and IGF-1 production (Inagaki et al., 2008; Kubicky et al., 2012). The possibility of similar effects in dairy cows was assessed in plasma samples collected during the basal period and on $\mathrm{d} 1,3$, and 8 of infusion. The plasma GH concentration decreased over the infusion period in both groups (Figure 5A; Time, $P=0.005)$ but tended to remain elevated in the FGF21 group relative to the control group (FGF21, $P$ $=0.091$ ). On the other hand, plasma IGF-1 increased steadily in the control group but remained invariant in the FGF21 group $($ FGF21 $\times$ Time, $P=0.042)$. This effect on plasma IGF-1 was not associated with altered hepatic expression of IGF1, the liver-specific GH receptor transcript GHR1A, or its signaling inhibitor SOCS2 (Figure 5B). In contrast, FGF21 treatment increased hepatic expression of the inhibitor of $\mathrm{GH}$ receptor trafficking, LEPROT (Figure 5B; FGF21, $P=0.02$ ).

\section{DISCUSSION}

Mobilization of lipid reserves after parturition makes the coexistence of productivity and energy insufficiency possible in high-yielding dairy cows, but it also can be maladaptive (Bell, 1995; Drackley et al., 2001). This is indicated by the persistence of excessively elevated concentrations of fatty acids in plasma followed by their accumulation in the form of triglyceride in nonadipose tissue (Drackley et al., 2001; Bobe et al., 2004). Triglyceride accumulation is particularly detrimental in the liver, where it impairs essential functions such as gluconeogenesis and promotes the synthesis of drivers of peripheral insulin resistance such as ceramides (Rukkwamsuk et al., 1999; McFadden and Rico, 2019). Hepatic lipidosis is also associated with postparturient disorders, including subclinical and clinical ketosis and poor reproductive performance (Drackley et al., 2001; Geelen and Wensing, 2006). Exogenous FGF21 therapy attenuates lipid mobilization and hepatic lipidosis in rodents (Xu et al., 2009a; Li et al., 2014; Park et al., 2016), but it was unknown at the start of this work whether these actions would take place in energydeficient, early-lactating dairy cows and whether they would occur without negative effects on performance.

We addressed these questions by treating dairy cows with LY2405319, a human FGF21 variant retaining full in vivo activity (Adams et al., 2013; Kharitonenkov et al., 2013); LY2405319 is identical to native human FGF21 except for the removal of the first $4 \mathrm{~N}$-terminal AA (HPIP) and the introduction of the point mutations L118C, A134C, and S167A to improve production in yeast (Kharitonenkov et al., 2013). Human FGF21 was available in the gram amounts needed for work in dairy cows, whereas bovine FGF21 was commercially available only in microgram amounts. This variant is bioactive in a range of species, including rhesus monkeys and mice (Adams et al., 2013; Kharitonenkov et al., 2013). Moreover, it produces metabolic responses in the mouse that are identical to those observed with mouse FGF21 (Kharitonenkov et al., 2013); therefore, it is likely capable of eliciting most if not all of the effects of bovine FGF21. We used this human variant

Table 3. Effect of chronic administration of fibroblast growth factor-21 (FGF21) on final BW, BCS, and milk composition in lactating dairy cows ${ }^{1}$

\begin{tabular}{|c|c|c|c|c|c|c|}
\hline \multirow[b]{2}{*}{ Variable } & \multicolumn{2}{|c|}{ Treatment } & \multirow[b]{2}{*}{$\mathrm{SD}$} & \multicolumn{3}{|c|}{$P$-value } \\
\hline & Control & FGF21 & & FGF21 & Time & FGF21 $\times$ Time \\
\hline Final $\mathrm{BW}^{2}(\mathrm{~kg})$ & 594.6 & 586.2 & 27.0 & 0.59 & - & - \\
\hline Final $\mathrm{BCS}^{2}$ & 3.0 & 3.2 & 0.2 & 0.32 & - & - \\
\hline \multicolumn{7}{|l|}{ Milk $^{3}$} \\
\hline $3.5 \% \mathrm{FCM}^{4}(\mathrm{~kg})$ & 54.4 & 52.6 & 4.3 & 0.57 & 0.01 & 0.80 \\
\hline Lactose $(\%)$ & 4.9 & 4.9 & 0.1 & 0.68 & 0.02 & 0.74 \\
\hline Fat $(\%)$ & 5.8 & 5.6 & 0.8 & 0.74 & 0.01 & 0.99 \\
\hline Protein (\%) & 2.6 & 2.8 & 0.0 & 0.004 & 0.06 & 0.89 \\
\hline
\end{tabular}

${ }^{1}$ Dairy cows received a constant i.v. infusion of excipient (control, $\mathrm{n}=6$ ) or human FGF21 (6.3 mg $/ \mathrm{kg}$ of metabolic BW per day, $\mathrm{n}=7$ ) starting on d $15.6 \pm 2.2$ of lactation and lasting for 9 consecutive days.

${ }^{2}$ Final BW and BCS $(1=$ thin, 5 = fat $)$ were measured at the end of the infusion period.

${ }^{3}$ Milk components were analyzed at each milking and averaged by day. Values represent the overall mean during the infusion period.

${ }^{4} 3.5 \% \mathrm{FCM}=0.4324 \times$ milk kg $+(16.218 \times$ milk fat $\mathrm{kg})$. 
A

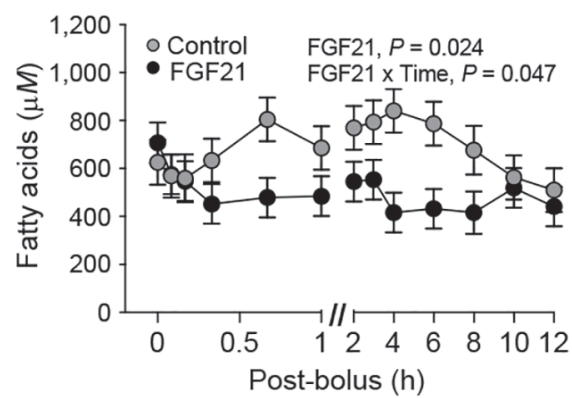

C

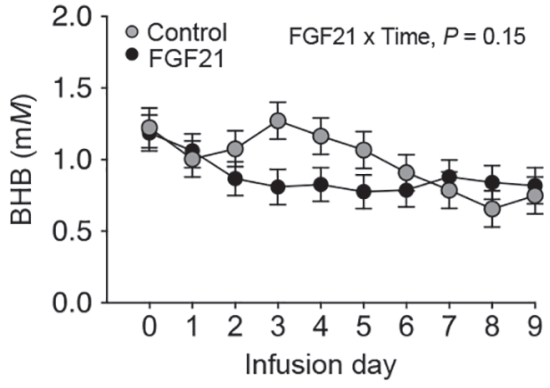

B

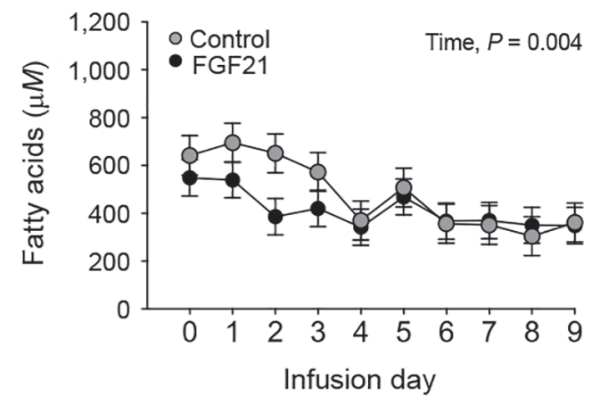

D

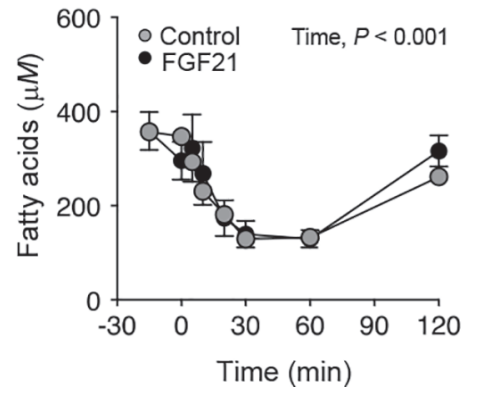

Figure 3. Effect of chronic administration of fibroblast growth factor-21 (FGF21) on lipid metabolism. An excipient (control) or human FGF21 solution was given i.v. as boluses on d $12.6 \pm 2.2$ of lactation (FGF21 dose $=3 \mathrm{mg} / \mathrm{kg}$ of BW) and as constant infusions (FGF21 dose $=6.3 \mathrm{mg} / \mathrm{kg}$ of metabolic BW per day) starting on d $14.6 \pm 2.2$. (A) Blood samples were collected over the 12-h period following the bolus, and plasma was analyzed for fatty acid concentration. Each point represents the LSM \pm SE of 6 to 7 cows. The significant effects of FGF21 and FGF21 $\times$ Time are reported. (B) Blood samples were collected daily over the 9-d constant infusion, and plasma was analyzed for concentrations of fatty acids. Each point represents the LSM \pm SE of 6 to 7 cows. The significant effect of Time is reported. (C) Blood samples were collected daily over the 9-d constant infusion, and plasma was analyzed for concentrations of BHB. Each point represents the LSM \pm SE of 6 to 7 cows. The $P$-value for FGF21 $\times$ Time is reported. (D) A glucose tolerance test was administered on d 8 of the constant infusion. Blood samples were collected at set time points before and after administration of glucose $(0.25 \mathrm{~g} / \mathrm{kg}$ of BW). Plasma was analyzed for fatty acid concentrations, and the response area was calculated. Each point for fatty acid concentration and each bar for the fatty acid response area represent the LSM $\pm \mathrm{SE}$ of 6 to 7 cows per treatment.

in an experimental design combining bolus and chronic administration directly into the vascular system. Intravenous bolus administration had the dual benefit of confirming human FGF21 bioactivity in cattle (Krumm et al., 2019) and allowing an estimation of its kinetics in the vascular compartment. This analysis yielded an estimated elimination $t_{1 / 2}$ of $3.2 \mathrm{~h}$, which is in the same range as values obtained for native human FGF21 of $1.5 \mathrm{~h}$ in the mouse and $2 \mathrm{~h}$ in rhesus monkeys (Kharitonenkov et al., 2007; Xu et al., 2009b). We opted for i.v. rather than s.c. administration during the chronic phase to minimize loss related to incomplete transport into the vascular compartment and, more important, to limit proteolysis. Recent studies in mice and cynomolgus monkeys showed that human FGF21 is highly susceptible to cleavage of the last $10 \mathrm{AA}$ and identified fibroblast activation protein as the responsible endopeptidase (Hecht et al., 2012; Hager et al., 2013). A similar situation could arise for bovine FGF21 because it also contains the C-terminal fibroblast activation protein proteolytic site. The loss of these AA ablates bioactivity, owing to the absolute requirement of the Cterminal region of FGF21 in recognizing its obligatory coreceptor $\beta$-klotho (Micanovic et al., 2009; Yie et al., 2012). Our data, however, suggested that this proteolytic cleavage is rather limited under our experimental conditions because plasma FGF21 concentrations detected by the intact assay, including in cows receiving human FGF21, did not differ significantly from those measured by the total assay.

Peripheral insulin resistance is regarded as one of the key adaptations of early lactation in dairy cows (Bell, 1995; Boisclair et al., 2006; De Koster and Opsomer, 2013). Insulin resistance creates a metabolic milieu favoring mammary glucose uptake, where it is used predominantly to synthesize lactose, the ultimate determi- 
nant of milk volume (Bell and Bauman, 1997). On the other hand, FGF21 has been shown to reverse insulin resistance in rodents and primates suffering from type 2 diabetes or obesity (Xu et al., 2009a; Adams et al., 2013). Accordingly, one concern with chronic FGF21 therapy in dairy cows was reduced milk production arising as a consequence of its insulin-sensitizing effects. Chronic FGF21 therapy, however, did not alter milk production assessed as either milk yield or ECM yield. Absence of detrimental effects on milk production may relate to the inability of FGF21 to counter insulin resistance in energy-deficient, early-lactating dairy cows, as suggested by unaffected plasma glucose and insulin, glucose disposal during GTT, and adiponectin produc-

A
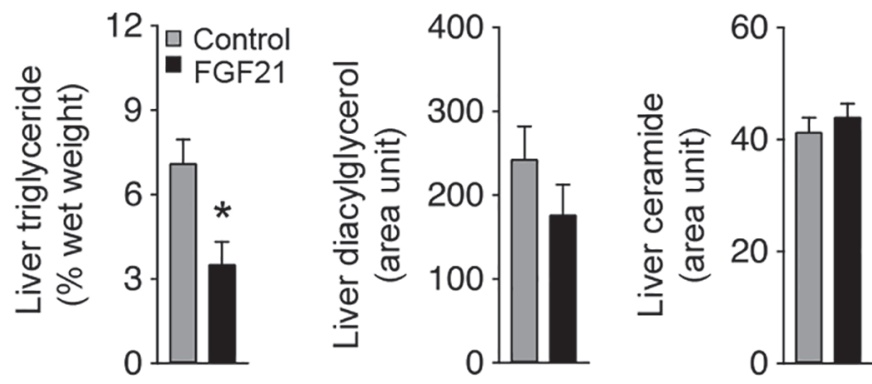

B

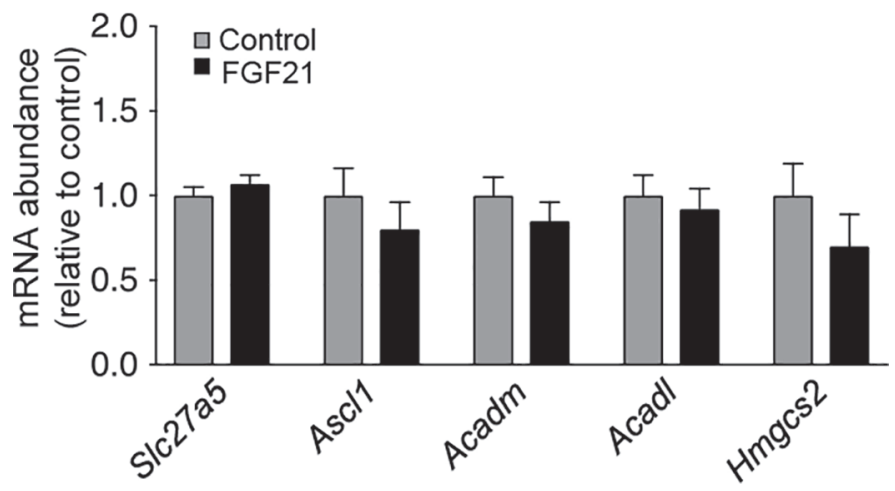

Figure 4. Effect of chronic administration of fibroblast growth factor-21 (FGF21) on liver lipids. Dairy cows received a constant i.v. infusion of an excipient (control) or human FGF21 $(6.3 \mathrm{mg} / \mathrm{kg}$ of metabolic BW per day) starting on d $14.6 \pm 2.2$ of lactation and lasting for 9 consecutive days. (A) Biopsies of liver were obtained from dairy cows on d 9 of infusion and analyzed for total triglyceride, diacylglycerol, and ceramide. Each bar represents the LSM $\pm \mathrm{SE}$ of the indicated variable $(\mathrm{n}=6$ cows $)$. ${ }^{*} P<0.036$. (B) Total $\mathrm{RNA}$ was isolated from the liver biopsies collected on d 9 of infusion and analyzed for the mRNA abundance of indicated genes. Expression of each gene is given relative to the control, with each bar representing the $\mathrm{LSM} \pm \mathrm{SE}$ of mRNA abundance for the indicated gene $(n=6$ cows).
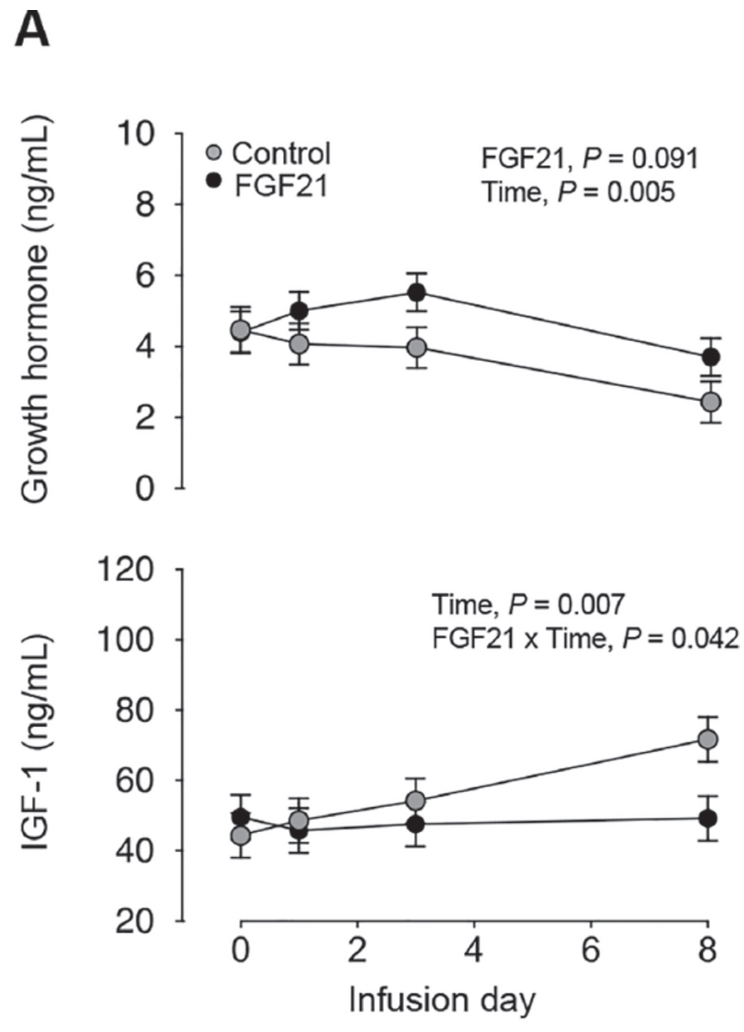

B

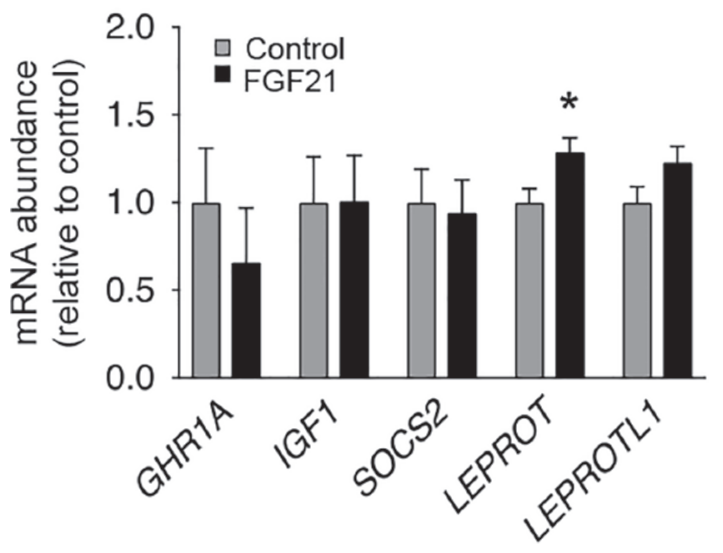

Figure 5. Effect of a chronic increase in plasma fibroblast growth factor-21 (FGF21) on growth hormone and IGF-1. Dairy cows received a constant i.v. infusion of an excipient (control) or human FGF21 (6.3 $\mathrm{mg} / \mathrm{kg}$ of metabolic BW per day) starting on d $14.6 \pm 2.2$ of lactation and lasting for 9 consecutive days. (A) Blood samples were collected before and on d 1, 3, and 8 of the infusion, and plasma was analyzed for the concentration of growth hormone and IGF-1. Each point represents the LSM \pm SE of 6 to 7 cows. The significant effects of FGF21, Time, and FGF21 × Time interaction are reported. (B) Total RNA was isolated from the liver biopsies collected on d 9 of infusion and analyzed for the mRNA abundance of indicated genes. Expression of each gene is given relative to the control, with each bar representing the $\mathrm{LSM} \pm \mathrm{SE}$ of mRNA abundance for the indicated gene $(\mathrm{n}=6$ cows). ${ }^{*} P=0.02$. 
tion (Krumm et al., 2019). Fibroblast growth factor-21 therapy has also been shown to depress voluntary feed intake in monkeys (Adams et al., 2013; Talukdar et al., 2016), raising the possibility that chronic treatment would exacerbate the negative energy balance of early lactation. This concern appears unwarranted because FGF21-treated cows did not experience reduced appetite, greater energy insufficiency, or lower BW and BCS at the end of treatment.

Liver accumulates triglyceride in early lactation because it takes up fatty acids in proportion to circulating levels, and this uptake outstrips its oxidative and secretory capacity (Drackley et al., 2001). Our data showed a $50 \%$ reduction in hepatic triglyceride levels in FGF21-treated cows. A similar effect in mice has been traced to reciprocal actions on pathways responsible for triglyceride synthesis and disposal. With respect to synthesis, FGF21 limits triglyceride accumulation in the mouse liver in part by inhibiting de novo fatty acid synthesis (Xu et al., 2009a; Fisher et al., 2014); this action cannot account for our results because this biosynthetic pathway is negligible in the ruminant liver (Bergen and Mersmann, 2005). More relevant to the dairy cow is the ability of FGF21 to reduce incorporation of adipose tissue-derived fatty acids into liver triglyceride. For example, mice lacking the transcription factor CREBH are unable to produce FGF21 upon fasting and experience increased lipolysis in adipose tissue, fatty acids in plasma, and triglyceride accumulation in liver; all 3 defects were corrected upon adenovirus-driven re-expression of FGF21 (Inagaki et al., 2007; Li et al., 2014; Park et al., 2016). Consistent with repressive effects of FGF21 on lipolysis, fasted FGF21 knockout (KO) mice have elevated plasma fatty acids and increased lipolytic activity in adipose tissue relative to their wild-type counterparts (Badman et al., 2009; Hotta et al., 2009). This antilipolytic effect was recapitulated in vitro in mouse and human primary adipocytes, suggesting that it is the result of direct FGF21 action on adipose tissue (Arner et al., 2008; Li et al., 2009). Our data provide some support for inhibition of lipolysis as a causal mechanism of reduced liver triglyceride as FGF21-treated cows experienced significantly lower plasma fatty acids after bolus administration and a numerical reduction during chronic administration.

Fibroblast growth factor- 21 has also been shown to reduce liver lipid in rodents by stimulating fatty acid oxidation. Thus, FGF21 KO mice have more severe steatosis than their wild-type counterparts when fasted or consuming methionine- and choline-deficient diets, and this exacerbation is associated with depressed expression of lipid oxidative enzymes (e.g., $A S C L 1, A C A D M$, and $A D A D L)$, reduced rates of $\beta$-oxidation, and lower plasma BHB; remarkably, all of these effects were reversed when FGF21 KO mice received exogenous FGF21 therapy (Potthoff et al., 2009; Fisher et al., 2014; Tanaka et al., 2015). In contrast, we saw no effect of chronic FGF21 treatment on liver expression of key genes governing $\beta$-oxidation and, therefore, no evidence that increased $\beta$-oxidation accounts for reduced liver triglyceride in FGF21-treated cows. Finally, it is also possible that FGF21 stimulates VLDL secretion as mice with defective FGF21 expression accumulate less triglyceride in plasma when treated with the lipoprotein lipase inhibitor tyloxapol (Badman et al., 2009). Unlike oxidation, however, VLDL secretion is governed predominantly by posttranscriptional mechanisms (Choi and Ginsberg, 2011), and an assessment of the effect of FGF21 on VLDL secretion requires functional assays that were not possible in this work.

Early-lactating dairy cows experience a state of GH resistance as shown by depressed plasma IGF-1 despite elevated GH and by their inability to mount a robust GH-dependent increase in plasma IGF-1 (Rhoads et al., 2007). We and others have shown that one cause of GH resistance in liver is reduced GH receptor abundance as a consequence of decreased expression of the liver-specific GH receptor transcript GHR1A (Butler et al., 2003; Rhoads et al., 2007). Interestingly, FGF21overexpressing mice exhibit hallmarks of GH resistance (elevated GH secretion and reduced plasma level of IGF-1) and suffer from significant deficits in linear and BW growth (Inagaki et al., 2008). Reciprocally, chronically undernourished FGF21 KO mice maintain elevated plasma IGF-1 and greater body and tibial growth relative to their wild-type counterparts, and this protection is obliterated by chronic FGF21 treatment (Kubicky et al., 2012). Fibroblast growth factor-21 triggers GH resistance via postreceptor mechanisms by inducing proteins that interfere with either trafficking of the GH receptor to the membrane (e.g., LEPROT and LEPROTL1) or its signaling (e.g., SOCS2; Inagaki et al., 2008; Wu et al., 2013). Our data reveal similar antagonism of GH action in early-lactating dairy cows, as FGF21-treated cows had lower plasma IGF-1 despite a tendency for increased plasma GH, and suggest induction of LEPROT as a mechanism in the liver.

In summary, we showed that FGF21 treatment reduces hepatic triglyceride accumulation in early-lactating dairy cows in the absence of negative effects on appetite, circulating BHB, and milk production. Future studies are needed to confirm that reduced influx of adipose tissue-derived fatty acids is the predominant mechanism accounting for reduced liver triglyceride and to ascertain whether this reflects a direct effect on adipose tissue. 


\section{ACKNOWLEDGMENTS}

This material is based on work that is supported by the National Institute of Food and Agriculture, USDA (Washington, DC), under award number 2010-6520620683 and Hatch/Multistate projects under 1000962 and 1017053. A. Butterfield and J. W. Perfield II are paid employees of Eli Lilly and Company (Indianapolis, IN) and may own company stock or possess stock options. We thank Alexei Kharitonenkov (Novo Nordisk Research Center Indianapolis, Indianapolis, IN) for his interest in and support of this project. We also thank Katie M. Schoenberg (Elanco Animal Health, Greenfield, IN) for helpful discussion, Phillip Gondim for assisting with the animal work, Brittany L. Moore (Cornell University, Ithaca, NY) for performing metabolite assays, and Paul L. Milligan (Eli Lilly and Company, Indianapolis, IN) for assistance with the lipidomics analysis.

\section{REFERENCES}

Adams, A. C., C. A. Halstead, B. C. Hansen, A. R. Irizarry, J. A. Martin, S. R. Myers, V. L. Reynolds, H. W. Smith, V. J. Wroblewski, and A. Kharitonenkov. 2013. LY2405319, an engineered FGF21 variant, improves the metabolic status of diabetic monkeys. PLoS One 8:e65763.

Arner, P., A. Pettersson, P. J. Mitchell, J. D. Dunbar, A. Kharitonenkov, and M. Ryden. 2008. FGF21 attenuates lipolysis in human adipocytes - A possible link to improved insulin sensitivity. FEBS Lett. 582:1725-1730.

Badman, M. K., A. Koester, J. S. Flier, A. Kharitonenkov, and E. Maratos-Flier. 2009. Fibroblast growth factor 21-deficient mice demonstrate impaired adaptation to ketosis. Endocrinology 150:4931-4940.

Bell, A. W. 1995. Regulation of organic nutrient metabolism during transition from late pregnancy to early lactation. J. Anim. Sci. 73:2804-2819.

Bell, A. W., and D. E. Bauman. 1997. Adaptations of glucose metabolism during pregnancy and lactation. J. Mammary Gland Biol. Neoplasia 2:265-278.

Bergen, W. G., and H. J. Mersmann. 2005. Comparative aspects of lipid metabolism: Impact on contemporary research and use of animal models. J. Nutr. 135:2499-2502.

Block, S. S., W. R. Butler, R. A. Ehrhardt, A. W. Bell, M. E. Van Amburgh, and Y. R. Boisclair. 2001. Decreased concentration of plasma leptin in periparturient dairy cows is caused by negative energy balance. J. Endocrinol. 171:339-348.

Bobe, G., J. W. Young, and D. C. Beitz. 2004. Invited review: Pathology, etiology, prevention, and treatment of fatty liver in dairy cows. J. Dairy Sci. 87:3105-3124.

Boisclair, Y. R., S. R. Wesolowski, J. W. Kim, and R. A. Ehrhardt. 2006. Roles of growth hormone and leptin in the periparturient dairy cow. Pages 327-346 in Proc. Xth International Symposium on Ruminant Physiology. Wageningen Academic Publishers, Wageningen, the Netherlands.

BonDurant, L. D., and M. J. Potthoff. 2018. Fibroblast growth factor 21: A versatile regulator of metabolic homeostasis. Annu. Rev. Nutr. 38:173-196.

Butler, S. T., A. L. Marr, S. H. Pelton, R. P. Radcliff, M. C. Lucy, and W. R. Butler. 2003. Insulin restores GH responsiveness during lactation-induced negative energy balance in dairy cattle: Effects on expression of IGF-I and GH receptor 1A. J. Endocrinol. $176: 205-217$.
Caixeta, L. S., S. L. Giesy, C. S. Krumm, J. W. Perfield II, A. Butterfield, K. M. Schoenberg, D. C. Beitz, and Y. R. Boisclair. 2017. Effect of circulating glucagon and free fatty acids on hepatic FGF21 production in dairy cows. Am. J. Physiol. Regul. Integr. Comp. Physiol. 313:R526-R534.

Choi, S. H., and H. N. Ginsberg. 2011. Increased very low density lipoprotein (VLDL) secretion, hepatic steatosis, and insulin resistance. Trends Endocrinol. Metab. 22:353-363.

De Koster, J. D., and G. Opsomer. 2013. Insulin resistance in dairy cows. Vet. Clin. North Am. Food Anim. Pract. 29:299-322.

Drackley, J. K., T. R. Overton, and G. N. Douglas. 2001. Adaptations of glucose and long-chain fatty acid metabolism in liver of dairy cows during the periparturient period. J. Dairy Sci. 84(ESuppl.):E100-E112.

Ehrhardt, R. A., R. M. Slepetis, A. W. Bell, and Y. R. Boisclair. 2001. Maternal leptin is elevated during pregnancy in sheep. Domest. Anim. Endocrinol. 21:85-96.

Estridge, T. B., A. B. Dey, C. Reidy, X. Yu, Y. Zhang, M. Hartley, P. L. Milligan, N. Jin, M. C. Kowala, J. K. Leohr, A. J. Fretland, T. E. Mabry, D. Luffer-Atlas, and M. J. Luo. 2017. Identification of 4-aminopyrazolopyrimidine metabolite that may contribute to the hypolipidemic effects of LY2584702 in Long Evans diet-induced obese rats. J. Pharmacol. Exp. Ther. 362:108-118.

Fisher, F. M., P. C. Chui, I. A. Nasser, Y. Popov, J. C. Cunniff, T. Lundasen, A. Kharitonenkov, D. Schuppan, J. S. Flier, and E. Maratos-Flier. 2014. Fibroblast growth factor 21 limits lipotoxicity by promoting hepatic fatty acid activation in mice on methionine and choline-deficient diets. Gastroenterology 147:1073-1083.

Fisher, F. M., and E. Maratos-Flier. 2016. Understanding the physiology of FGF21. Annu. Rev. Physiol. 78:223-241.

Gaich, G., J. Y. Chien, H. Fu, L. C. Glass, M. A. Deeg, W. L. Holland, A. Kharitonenkov, T. Bumol, H. K. Schilske, and D. E. Moller. 2013. The effects of LY2405319, an FGF21 analog, in obese human subjects with type 2 diabetes. Cell Metab. 18:333-340.

Geelen, M. J., and T. Wensing. 2006. Studies on hepatic lipidosis and coinciding health and fertility problems of high-producing dairy cows using the "Utrecht fatty liver model of dairy cows". A review. Vet. Q. 28:90-104.

Giesy, S. L., B. Yoon, W. B. Currie, J. W. Kim, and Y. R. Boisclair. 2012. Adiponectin deficit during the precarious glucose economy of early lactation in dairy cows. Endocrinology 153:5834-5844.

Hager, T., C. Spahr, J. Xu, H. Salimi-Moosavi, and M. Hall. 2013. Differential enzyme-linked immunosorbent assay and ligand-binding mass spectrometry for analysis of biotransformation of protein therapeutics: Application to various FGF21 modalities. Anal. Chem. 85:2731-2738.

Hecht, R., Y. S. Li, J. Sun, E. Belouski, M. Hall, T. Hager, J. Yie, W. Wang, D. Winters, S. Smith, C. Spahr, L. T. Tam, Z. Shen, S. Stanislaus, N. Chinookoswong, Y. Lau, A. Sickmier, M. L. Michaels, T. Boone, M. M. Veniant, and J. Xu. 2012. Rationale-based engineering of a potent long-acting FGF21 analog for the treatment of type 2 diabetes. PLoS One 7:e49345.

Hotta, Y., H. Nakamura, M. Konishi, Y. Murata, H. Takagi, S. Matsumura, K. Inoue, T. Fushiki, and N. Itoh. 2009. Fibroblast growth factor 21 regulates lipolysis in white adipose tissue but is not required for ketogenesis and triglyceride clearance in liver. Endocrinology 150:4625-4633

Inagaki, T., P. Dutchak, G. Zhao, X. Ding, L. Gautron, V. Parameswara, Y. Li, R. Goetz, M. Mohammadi, V. Esser, J. K. Elmquist, R. D. Gerard, S. C. Burgess, R. E. Hammer, D. J. Mangelsdorf, and S. A. Kliewer. 2007. Endocrine regulation of the fasting response by PPAR $\alpha$-mediated induction of fibroblast growth factor 21. Cell Metab. 5:415-425.

Inagaki, T., V. Y. Lin, R. Goetz, M. Mohammadi, D. J. Mangelsdorf, and S. A. Kliewer. 2008. Inhibition of growth hormone signaling by the fasting-induced hormone FGF21. Cell Metab. 8:77-83.

Itoh, N., H. Ohta, Y. Nakayama, and M. Konishi. 2016. Roles of FGF signals in heart development, health, and disease. Front. Cell Dev. Biol. 4:110.

Kharitonenkov, A., J. M. Beals, R. Micanovic, B. A. Strifler, R. Rathnachalam, V. J. Wroblewski, S. Li, A. Koester, A. M. Ford, T. 
Coskun, J. D. Dunbar, C. C. Cheng, C. C. Frye, T. F. Bumol, and D. E. Moller. 2013. Rational design of a fibroblast growth factor 21-based clinical candidate, LY2405319. PLoS One 8:e58575.

Kharitonenkov, A., V. J. Wroblewski, A. Koester, Y. F. Chen, C. K. Clutinger, X. T. Tigno, B. C. Hansen, A. B. Shanafelt, and G. J Etgen. 2007. The metabolic state of diabetic monkeys is regulated by fibroblast growth factor-21. Endocrinology 148:774-781.

Krumm, C. S., S. L. Giesy, L. S. Caixeta, J. W. Perfield II, H. Sauerwein, B. L. Moore, and Y. R. Boisclair. 2019. Fibroblast growth factor 21 (FGF21) administration to early-lactating dairy cows: Effects on signaling and indices of insulin action. J. Dairy Sci. 102:11586-11596. https://doi.org/10.3168/jds.2019-16695.

Kubicky, R. A., S. Wu, A. Kharitonenkov, and F. De Luca. 2012. Role of fibroblast growth factor 21 (FGF21) in undernutrition-related attenuation of growth in mice. Endocrinology 153:2287-2295.

Leury, B. J., L. H. Baumgard, S. S. Block, N. Segoale, R. A. Ehrhardt, R. P. Rhoads, D. E. Bauman, A. W. Bell, and Y. R. Boisclair. 2003. Effect of insulin and growth hormone on plasma leptin in periparturient dairy cows. Am. J. Physiol. Regul. Integr. Comp. Physiol. 285:R1107-R1115.

Li, X., H. Ge, J. Weiszmann, R. Hecht, Y. S. Li, M. M. Veniant, J. Xu, X. Wu, R. Lindberg, and Y. Li. 2009. Inhibition of lipolysis may contribute to the acute regulation of plasma FFA and glucose by FGF21 in ob/ob mice. FEBS Lett. 583:3230-3234.

Li, Y., K. Wong, A. Giles, J. Jiang, J. W. Lee, A. C. Adams, A. Kharitonenkov, Q. Yang, B. Gao, L. Guarente, and M. Zang. 2014. Hepatic SIRT1 attenuates hepatic steatosis and controls energy balance in mice by inducing fibroblast growth factor 21 . Gastroenterology 146:539-549.

McFadden, J. M., and J. E. Rico. 2019. Ceramide, insulin sensitivity and the homeorhetic control of lactation: Discovering the inner sphinx of the dairy cow. J. Dairy Sci. 102:7619-7639. https://doi .org/10.3168/jds.2018-16095.

Micanovic, R., D. W. Raches, J. D. Dunbar, D. A. Driver, H. A. Bina, C. D. Dickinson, and A. Kharitonenkov. 2009. Different roles of $\mathrm{N}$ - and C- termini in the functional activity of FGF21. J. Cell. Physiol. 219:227-234.

Nafikov, R. A., B. N. Ametaj, G. Bobe, K. J. Koehler, J. W. Young, and D. C. Beitz. 2006. Prevention of fatty liver in transition dairy cows by subcutaneous injections of glucagon. J. Dairy Sci. 89:1533-1545.

NRC. 2001. Nutrient Requirements of Dairy Cattle. 7th rev. ed. Natl. Acad. Press, Washington, DC.

Park, J. G., X. Xu, S. Cho, K. Y. Hur, M. S. Lee, S. Kersten, and A. H. Lee. 2016. CREBH-FGF21 axis improves hepatic steatosis by suppressing adipose tissue lipolysis. Sci. Rep. 6:27938.

Pillon, N. J., S. Frendo-Cumbo, M. R. Jacobson, Z. Liu, P. L. Milligan, H. Hoang Bui, J. R. Zierath, P. J. Bilan, J. T. Brozinick, and A. Klip. 2018. Sphingolipid changes do not underlie fatty acid-evoked GLUT4 insulin resistance nor inflammation signals in muscle cells. J. Lipid Res. 59:1148-1163.

Potthoff, M. J., T. Inagaki, S. Satapati, X. Ding, T. He, R. Goetz, M. Mohammadi, B. N. Finck, D. J. Mangelsdorf, S. A. Kliewer, and S. C. Burgess. 2009. FGF21 induces PGC-1alpha and regu- lates carbohydrate and fatty acid metabolism during the adaptive starvation response. Proc. Natl. Acad. Sci. USA 106:10853-10858.

Rhoads, R. P., J. W. Kim, M. E. Van Amburgh, R. A. Ehrhardt, S. J. Frank, and Y. R. Boisclair. 2007. Effect of nutrition on the GH responsiveness of liver and adipose tissue in dairy cows. J. Endocrinol. 195:49-58.

Rukkwamsuk, T., T. Wensing, and M. J. Geelen. 1999. Effect of fatty liver on hepatic gluconeogenesis in periparturient dairy cows. J. Dairy Sci. 82:500-505.

Schoenberg, K. M., S. L. Giesy, K. J. Harvatine, M. R. Waldron, C. Cheng, A. Kharitonenkov, and Y. R. Boisclair. 2011. Plasma FGF21 is elevated by the intense lipid mobilization of lactation. Endocrinology 152:4652-4661.

Sechen, S. J., S. N. McCutcheon, and D. E. Bauman. 1989. Response to metabolic challenges in early lactation dairy cows during treatment with bovine somatotropin. Domest. Anim. Endocrinol. 6:141-154.

Talukdar, S., Y. Zhou, D. Li, M. Rossulek, J. Dong, V. Somayaji, Y Weng, R. Clark, A. Lanba, B. M. Owen, M. B. Brenner, J. K Trimmer, K. E. Gropp, J. R. Chabot, D. M. Erion, T. P. Rolph, B. Goodwin, and R. A. Calle. 2016. A long-acting FGF21 molecule, PF-05231023, decreases body weight and improves lipid profile in non-human primates and type 2 diabetic subjects. Cell Metab. 23:427-440.

Tanaka, N., S. Takahashi, Y. Zhang, K. W. Krausz, P. B. Smith, A. D. Patterson, and F. J. Gonzalez. 2015. Role of fibroblast growth factor 21 in the early stage of NASH induced by methionine- and choline-deficient diet. Biochim. Biophys. Acta 1852:1242-1252.

Vernon, R. G. 2005. Lipid metabolism during lactation: A review of adipose tissue-liver interactions and the development of fatty liver. J. Dairy Res. 72:460-469.

Wu, S., T. Grunwald, A. Kharitonenkov, J. Dam, R. Jockers, and F. De Luca. 2013. Increased expression of fibroblast growth factor 21 (FGF21) during chronic undernutrition causes growth hormone insensitivity in chondrocytes by inducing leptin receptor overlapping transcript (LEPROT) and leptin receptor overlapping transcriptlike 1 (LEPROTL1) expression. J. Biol. Chem. 288:27375-27383.

Xu, J., D. J. Lloyd, C. Hale, S. Stanislaus, M. Chen, G. Sivits, S. Vonderfecht, R. Hecht, Y. S. Li, R. A. Lindberg, J. L. Chen, D. Y. Jung, Z. Zhang, H. J. Ko, J. K. Kim, and M. M. Veniant. 2009a. Fibroblast growth factor 21 reverses hepatic steatosis, increases energy expenditure, and improves insulin sensitivity in diet-induced obese mice. Diabetes 58:250-259.

Xu, J., S. Stanislaus, N. Chinookoswong, Y. Y. Lau, T. Hager, J. Patel, H. Ge, J. Weiszmann, S. C. Lu, M. Graham, J. Busby, R. Hecht, Y. S. Li, Y. Li, R. Lindberg, and M. M. Veniant. 2009b. Acute glucose-lowering and insulin-sensitizing action of FGF21 in insulinresistant mouse models-Association with liver and adipose tissue effects. Am. J. Physiol. Endocrinol. Metab. 297:E1105-E1114.

Yie, J., W. Wang, L. Deng, L. T. Tam, J. Stevens, M. M. Chen, Y. Li, J. Xu, R. Lindberg, R. Hecht, M. Veniant, C. Chen, and M. Wang. 2012. Understanding the physical interactions in the FGF21/ FGFR/beta-Klotho complex: Structural requirements and implications in FGF21 signaling. Chem. Biol. Drug Des. 79:398-410. 